\title{
Resistance of Austenitic Stainless Steels to Ductility-Dip Cracking: Mechanisms
}

\author{
Both columnar $\delta$ (ferrite) grains with continuous $\gamma$ (austenite) along grain boundaries \\ and equiaxed $\delta$ grains resist cracking but not skeletal/lacy $\delta$, as often suggested
}

BY P. YU, J. MORROW, AND S. KOU

\begin{abstract}
In Ni-based alloys, precipitates that form along grain boundaries (GBs) during terminal solidification have been shown to pin GBs and resist GB sliding, which can cause ductility-dip cracking (DDC). As a result, it is often suggested that the stainless steel skeletal/lacy $\delta$ in a $\gamma$ matrix resists DDC because it pins GBs. In the present study, austenitic stainless steels $304,316,310$, and 321 were quenched with liquid Wood's metal $\left(75^{\circ} \mathrm{C}\right)$ during welding. Quenching captured the elevated-temperature microstructure and simultaneously induced cracking, thus revealing the mechanisms of the resistance to DDC. In addition, DDC was much higher in 310 than 304,316 , and 321 , which is consistent with results of conventional tests. Both 304 and 316 solidified as columnar $\delta$ grains, with continuous $\gamma$ formed along GBs soon after solidification to resist DDC along the GBs. 321 solidified as equiaxed grains of $\delta$ instead of columnar, and the tortuous GBs associated with equiaxed grains resisted DDC. 310, however, solidified as coarse, straight $\gamma$ grains with little $\delta$ along the GBs, and solidification GBs migrated to become locally straight. The resulting GBs were long, straight, and naked, which is ideal for DDC. In 304,316 , or 321 , skeletal/lacy $\delta$ in a $\gamma$ matrix did not exist in the fusion zone near the mushy zone, where DDC occurs. This proved skeletal/lacy $\delta$ cannot resist DDC as often suggested. Instead, the present study identified two new mechanisms of resistance to DDC: 1) formation of continuous or nearly continuous $\gamma$ along boundaries of columnar $\delta$ grains and 2) solidification as equiaxed $\delta$ grains.
\end{abstract}

\section{KEYWORDS}

- Ductility-Dip Cracking • Solidification Cracking

- Austenitic Stainless Steels • Welding • Ferrite

- Austenite • Quenching

\section{Introduction}

Because an alloy melts and solidifies over a range of temperatures during welding, a mushy zone $(S+L)$ forms be- tween the weld pool (L) and the fusion zone (S), and a partially melted zone $(\mathrm{S}+\mathrm{L})$ exists in the region of the workpiece around the weld pool as illustrated in Fig. 1 (Ref. 1). The mushy zone is semisolid, and it has little strength because grains or dendrites are not bonded to each other but separated by liquid films. It also has very limited ductility near the end of solidification, where little liquid is left to accommodate deformation. The region of the fusion zone near the mushy zone, represented by the shaded area in the fusion zone, can also have limited ductility. This is because a significant ductility drop can occur in an intermediate temperature range below the solidus temperature $\mathrm{T}_{S}$, often in the range of 0.6-0.9 $\mathrm{T}_{S}$ (Ref. 2).

Metals shrink upon solidification due to the higher density of solid than liquid, for example, $6.6 \%$ for $\mathrm{Al}$ and $4.0 \%$ for Fe (Ref. 3). Metals also shrink upon cooling due to thermal contraction (caused by the thermal expansion coefficient). Thus, the mushy zone, the partially melted zone, and the fusion zone all tend to shrink upon solidification and cooling during welding. However, they cannot shrink freely because they are connected to the much bigger and cooler workpiece. This obstructed shrinkage induces tension and hence cracking (Ref. 4). Cracking during welding includes solidification cracking $(S C)$ in the mushy zone, liquation cracking in the partially melted zone, and ductility-dip cracking (DDC) in the region of the fusion zone near the mushy zone, all of which are intergranular.

DDC can occur in an intermediate temperature range below the solidus temperature $\mathrm{T}_{\mathrm{S}}$, often between 0.6 and $0.9 \mathrm{~T}_{\mathrm{s}}$. In the case of stainless steels and Ni-based alloys, this translates to $800^{\circ}-1150^{\circ} \mathrm{C}$. DDC typically occurs in austenitic materials along nearly straight grain boundaries (GBs), which make crack propagation easy. It has been suggested that DDC occurs by GB shearing (Ref. 5) or GB sliding (Refs. 6-9), like creep but much faster and typically along a nearly straight GB (Ref. 2). Migration from a cellular or dendritic solidification grain boundary (SGB) to an essentially straight migrated grain boundary (MGB) can occur after solidification, presumably by diffusion to reduce the GB area and hence surface energy. Other theories have also been proposed for DDC, including GB embrittlement caused by impurities such as $S$ and $P$ segregating to GBs (Refs. 10-12). 


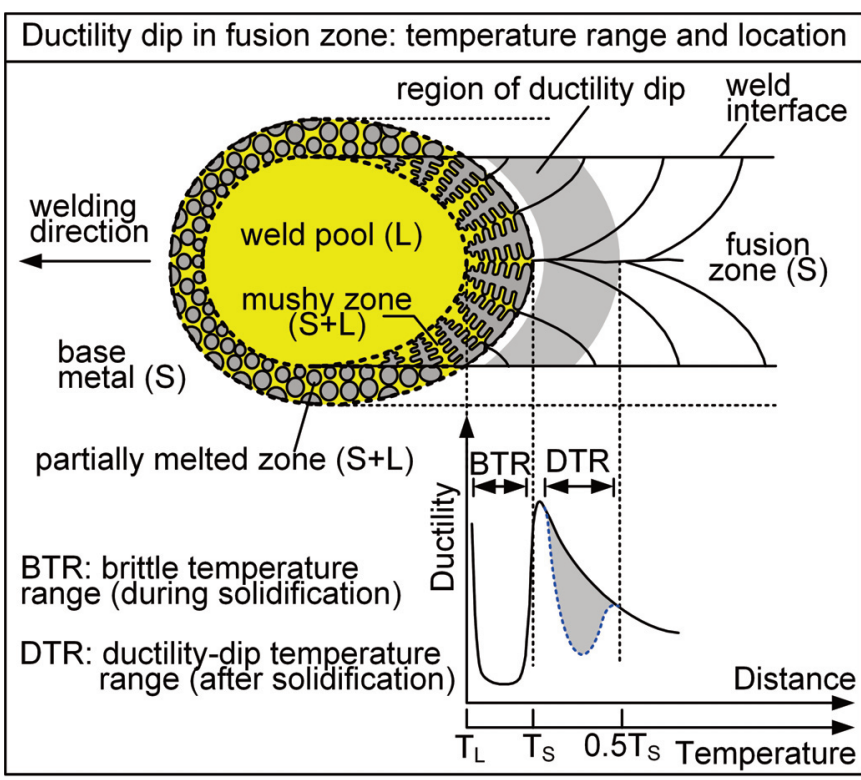

Fig. 1-Ductility dip in the region of the fusion zone near the mushy zone and the ductility-dip temperature range.

DDC in Ni-based alloys has been studied extensively. It often occurs along MGBs, which are straight and thus easy for crack propagation. Ramirez and Lippold (Refs. 6, 7) proposed the following mechanism for the resistance to DDC: If precipitates form at the end of solidification (such as $\mathrm{NbC}$ via a eutectic reaction), the GBs are pinned by these precipitates, resulting in a "tortuous" GB that resists sliding due to the mechanical locking effect of the tortuous boundary. This mechanism has been verified with welds of Ni-based alloys. DDC in stainless steels has not been studied as extensively. Arata et al. (Ref. 13) showed with the Varestraint test that 310 stainless steel is much more susceptible to DDC than 304, 316, and 321 stainless steels. Nissley et al. (Ref. 14) showed with the strain-tofracture test that 310 is much more susceptible to DDC than 304. Nishimoto et al. (Ref. 15) studied the effect of $S$ and $P$ on DDC in 310. Shibata et al. (Ref. 16) showed GB migration in 310 welds.

Kou and Le (Ref. 17) first demonstrated liquid-Sn quenching during welding and captured the microstructural evolution in stainless steels. Sn quenching was used by subsequent investigators (Refs. 18-27) to study welding of stainless steels.

Recently, Liu et al. (Ref. 28) first used liquid Wood's metal (Refs. 29, 30) for quenching during welding. Wood's metal (a eutectic alloy consisting of $50 \% \mathrm{Bi}, 26.7 \% \mathrm{~Pb}, 13.3 \% \mathrm{Sn}$, and

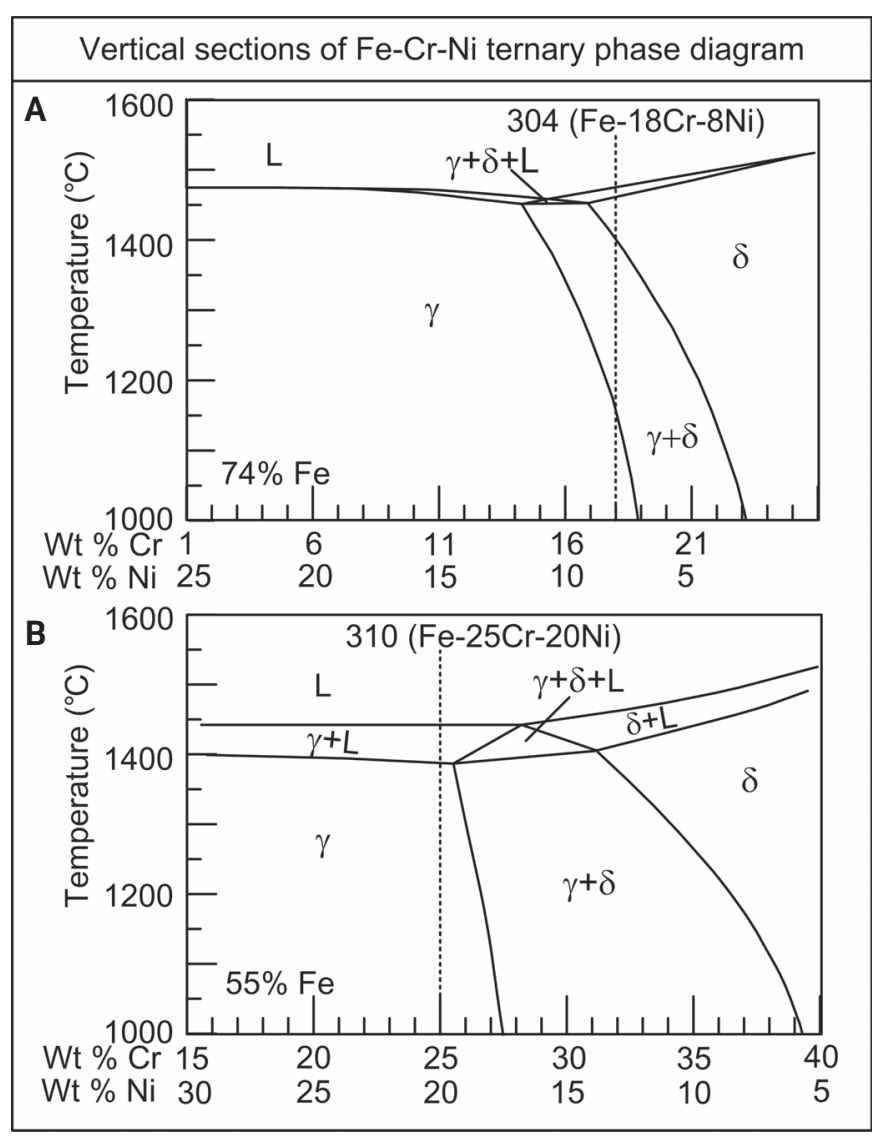

Fig. 2 - Vertical sections of Fe-Cr-Ni phase diagram: A - At 74 wt-\% Fe (Ref. 36); B - at 55 wt-\% Fe (Ref. 37).

$10 \% \mathrm{Cd}$ by weight) melts at $70^{\circ} \mathrm{C}$ (Ref. 30 ) and is thus cool enough for quenching $\mathrm{Al}$ alloys during welding (Ref. 28). Yu et al. (Ref. 31) and Liu et al. (Ref. 32) used Wood's metal quenching to study solidification cracking in stainless steels. The elevated-temperature microstructure revealed by Wood's metal quenching was significantly clearer than that by Sn quenching (Ref. 17). In-situ x-ray diffraction by synchrotron radiation (Refs. 33-35) is useful for studying microstructure evolution during welding. But Wood's metal quenching is simple and inexpensive enough to be used in any welding lab.

\section{Experimental Procedure}

Austenitic stainless steels 304, 310, 316, and 321 were

Table 1-Compositions of Stainless Steels in wt-\%

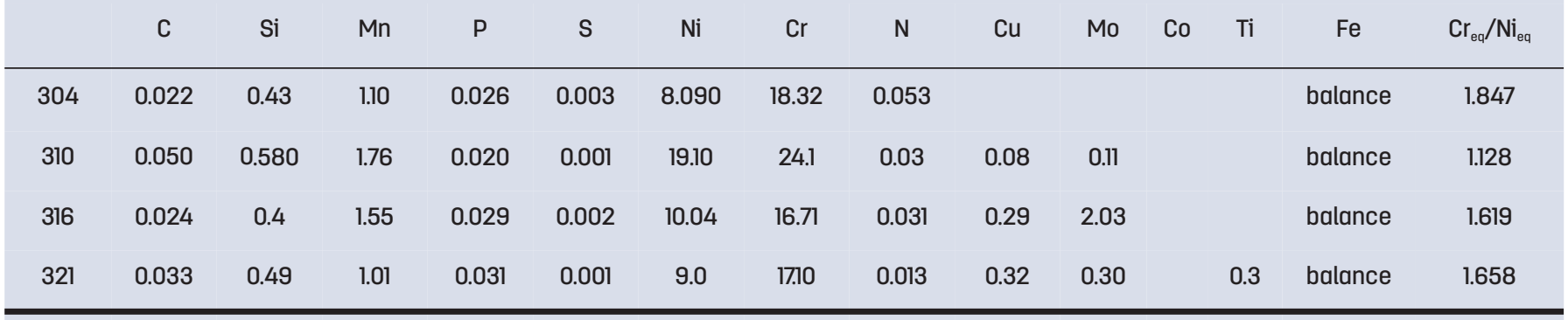


welded by the gas tungsten arc welding process. Their compositions are shown in Table 1 . They were quenched with Wood's metal $\left(75^{\circ} \mathrm{C}\right)$ during bead-on-plate welding. The workpiece was $102 \mathrm{~mm}$ (4 in.) long, $51 \mathrm{~mm}$ (2 in.) wide, and $1.6 \mathrm{~mm}(1 / 16$ in.) thick and welded along the centerline in the length direction. Welding was conducted from under the workpiece to provide room for quenching from above the workpiece. Direct current electrode negative was used with Ar shielding. The torch travel speed was 1.35 to $1.48 \mathrm{~mm} / \mathrm{s}$ (3.2 to $3.5 \mathrm{in.} / \mathrm{min}$ ), the welding current was 48 to $55 \mathrm{~A}$, and the voltage was 7.8 to $10 \mathrm{~V}$. The arc length was initially set at $2.3 \mathrm{~mm}$.

The resultant welds were cut, polished, and etched (Ref. 31). 304 and 316 were electrochemically etched with a solution consisting of $60 \mathrm{~g}$ of oxalic acid in $600 \mathrm{~mL}$ of water. The voltage was $10 \mathrm{~V}$, and the etching time was 15 s. 310 was etched with mixed acids consisting of $10 \mathrm{~mL} \mathrm{HNO}_{3}, 20 \mathrm{~mL}$ $\mathrm{HCl}$, and $30 \mathrm{~mL} \mathrm{H}_{2} \mathrm{O}$. The etched samples were examined by optical microscopy. Electron backscatter diffraction (EBSD) was conducted using a Thermo Scientific ${ }^{\mathrm{TM}}$ Lumis $^{\mathrm{TM}}$ EBSD detector installed on a JEOL JSM-7001F scanning electron microscope at Thermo Fisher Scientific in Fitchburg, Wis.

\section{Results and Discussion}

For convenience of discussion, the vertical sections of the ternary $\mathrm{Fe}-\mathrm{Cr}$-Ni phase diagram are shown at $74 \mathrm{wt}-\% \mathrm{Fe}$ in Fig. 2A for 304 ( Fe-18Cr-8Ni) (Ref. 36) and at $55 \mathrm{wt}-\% \mathrm{Fe}$ $(\sim \mathrm{Fe}-25 \mathrm{Cr}-20 \mathrm{Ni})$ in Fig. 2B for 310 (Ref. 37).

\section{Evidence of $\gamma$ along Boundaries between $\delta$ Dendrites}

Figure 3 compares, for 304, the room-temperature microstructure of the fusion zone and the elevated-temperature microstructure captured during welding. The welding direction is indicated. These longitudinal optical micrographs were taken at the top surfaces of the welds near their centerlines. In the room-temperature micrograph in Fig. 3A, the thick, dark broken line indicates the crater boundary near the centerline of the weld top surface, that is, the boundary between the crater of the weld and the fusion zone behind it. Two columnar grains are present in the micrograph, one on the left and the other on the right. As can be seen, skeletal (or vermicular) $\delta$-ferrite (SF) exists in the grain on the left while lacy (or lathy) $\delta$-ferrite (LF) exists in the grain on the right. This microstructure of skeletal/lacy $\delta$-ferrite in a matrix of austenite $\gamma$ is typical in the fusion zone of 304 stainless steel at room temperature. In either grain, the microstructure is continuous across the crater boundary because of epitaxial growth of the grains from the boundary into the weld pool when the arc was turned off.

The elevated-temperature micrograph in Fig. 3B differs dramatically from the room-temperature micrograph in Fig. 3A. First, dendrites of the primary solidification phase $\delta$ are visible in the mushy zone. The secondary dendrite arms are clear near the pool boundary but become unrecognizable behind it because of coarsening due to fast solid-state diffusion in a body-centered-cubic (BCC) structure like $\delta$. Second, behind the dark broken line, $\gamma$ starts to form along the bound-

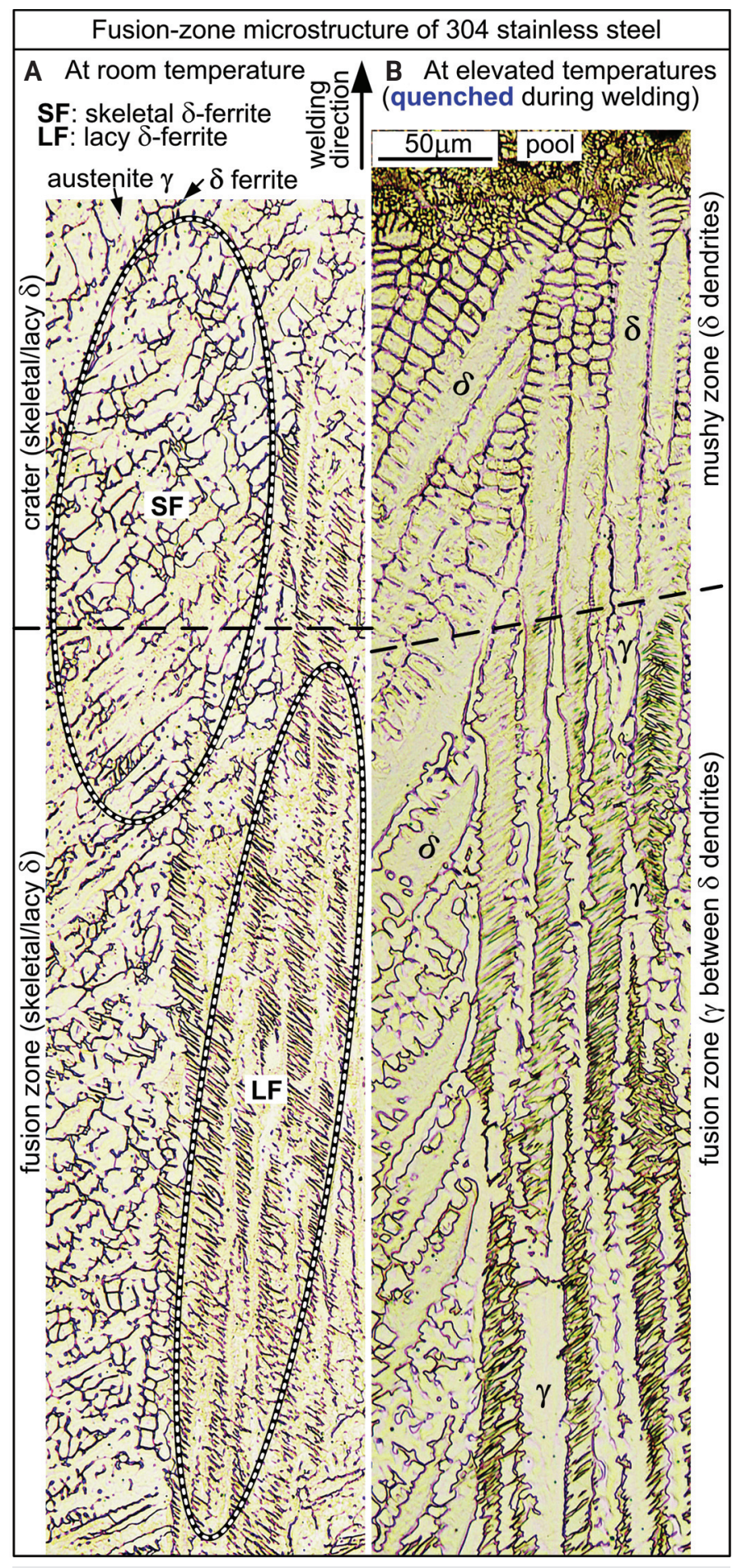

Fig. 3 - Longitudinal optical micrographs along the centerlines of the top surfaces of the 304 welds: $A-$ Room-temperature microstructure of a weld made without quenching showing skeletal/lacy $\delta$-ferrite; B - elevated-temperature microstructure of a weld captured by quenching during welding showing no skeletal/lacy $\delta$-ferrite in the fusion zone near the mushy zone, where DDC occurs during welding.

aries between $\delta$ dendrites by the $\delta \rightarrow \gamma$ transformation. The farther behind the line, the deeper $\gamma$ grows into $\delta$ dendrites. Since $\gamma$ grows deep into $\delta$ dendrites, bonding between $\delta$ den- 


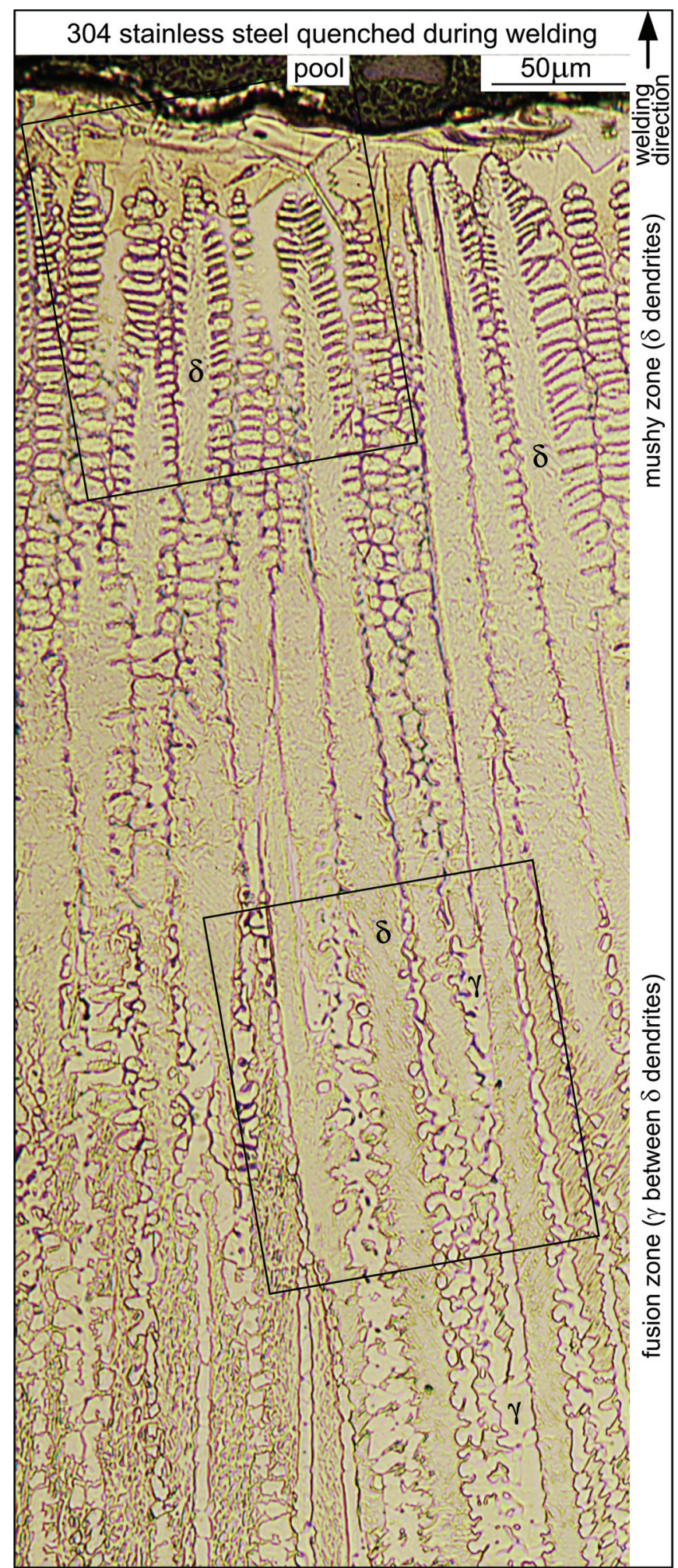

Fig. 4-Optical micrographs showing the elevated-temperature microstructure of 304 captured by quenching during welding. Boxed areas indicate the locations of EBSD analysis in Fig. 5.

drites is significantly strengthened. This suggests crack propagation in the solid state along the boundaries between $\delta$ dendrites, that is, DDC, is much more difficult.

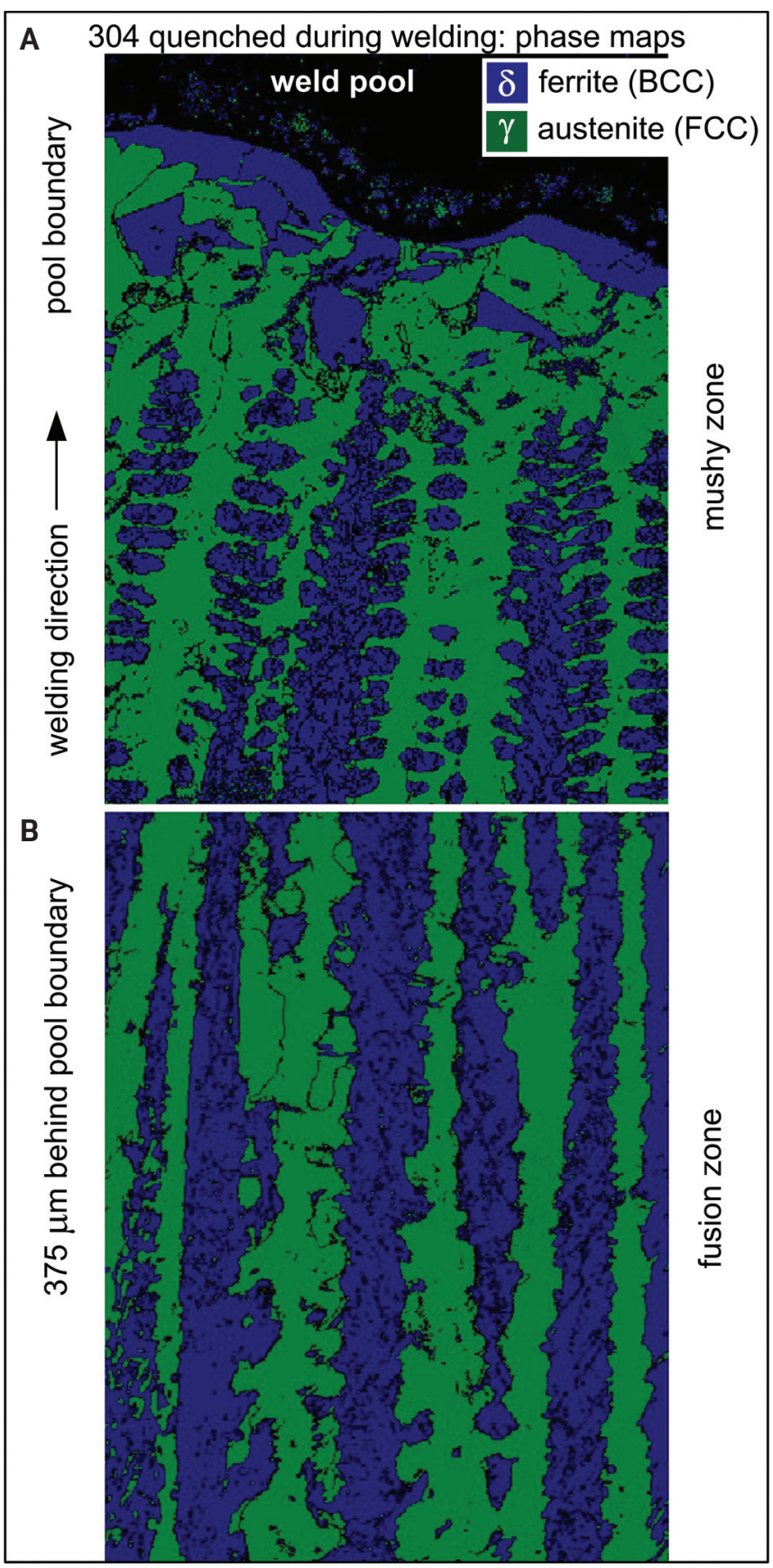

Fig. 5 - Phase maps shown by EBSD: A - Top boxed area in Fig. 4, that is, at the pool boundary; $B$ - bottom boxed area in Fig. 4, that is, at about $375 \mu \mathrm{m}$ behind the pool boundary.

It is thus obvious that the resistance to hot cracking cannot be interpreted based on the room-temperature microstructure of the fusion zone. This is why quenching during welding is needed to capture the elevated-temperature microstructure responsible for resisting DDC. The present study is believed to be the first to investigate DDC by quenching during welding.

Like in Fig. 3A, two columnar grains are present in Fig. 3B. Behind the dark broken line, the grain on the right shows $\gamma$ growing in specific directions into $\delta$-ferrite from the boundaries between $\delta$ dendrites. This inward growth of $\gamma$ into $\delta$, 
however, is not evident in the grain on the left. Inoue et al. (Ref. 19) showed the $\delta \rightarrow \gamma$ transformation can occur along the austenite habit plane into the $\delta$-ferrite dendrites if the Kurdjumov-Sachs orientation relationships exist between $\delta$-ferrite and the austenite $\gamma$, namely, $(110)_{\delta} / /(111)_{\gamma}$ and $[111]_{\delta} / /[110]_{\gamma}$. Had the 304 not been quenched during welding, the resultant $\delta$-ferrite morphology of the grain on the right would have been lacy similar to the LF region in Fig. 3A. In Fig. 3B, the Kurdjumov-Sachs relationships do not exist in the columnar grain on the left. Had the 304 not been quenched during welding, the resultant $\delta$-ferrite morphology of the grain on the left would have been skeletal, similar to the SF region in Fig. 3A.

\section{Confirmation of $\gamma$ along Boundaries between $\delta$ Dendrites}

Figure 4 is an optical micrograph of 304 quenched during welding, similar to that in Fig. 3B. Figure $5 \mathrm{~A}$ is the phase map of the top boxed area in Fig. 4 shown by EBSD. The dendrites are BCC, that is, $\delta$-ferrite. The regions between dendrites are FCC, that is, austenite $\gamma$. Figure 5B is the phase map of the bottom boxed area in Fig. 4. This area is about $375 \mu \mathrm{m}$ behind the pool boundary. Again, the dendrites are BCC, that is, $\delta$ ferrite, and the second phase that forms along the boundaries between $\delta$-ferrite dendrites is FCC, that is, austenite $\gamma$. Thus, the EBSD analysis has confirmed that in the fusion zone of 304 near the mushy zone, $\gamma$ forms along the boundaries between $\delta$-dendrites.

\section{Susceptibility to DDC Revealed by Quenching}

Figure 6 shows the macrographs of the stainless steels quenched during welding. Most of the liquid was pushed out of the weld pool by liquid Wood's metal during quenching. As shown, SC (cracking near the pool boundary) is much more in 310 than in 304, 316, and 321. This is consistent with the experimental results of Arata et al. (Ref. 38) and Senda et al. (Ref. 39) based on the Varestraint test as well as



Fig. 6 - Cracking induced by Wood's metal quenching: $A-304 ; B-316 ; C-321 ; D-310$. Cracking only occurs near the pool boundary in $A-C$, indicating mainly solidification cracking. Cracking also occurs far behind the pool boundary in $D$, indicating severe DDC as well as solidification cracking.
Liu et al. (Ref. 32) based on the transverse-motion weldability test. Figure 6 also shows DDC (cracking well behind the pool boundary) is much more severe in 310 than in 304 , 316, and 321. This is consistent with the experimental results of Arata et al. (Ref. 13) based on the Varestraint test and Nissley et al. (Ref. 14) based on the strain-to-fracture test. Thus, the relative susceptibility to DDC revealed by Wood's metal quenching during welding is consistent with that shown by conventional tests. 


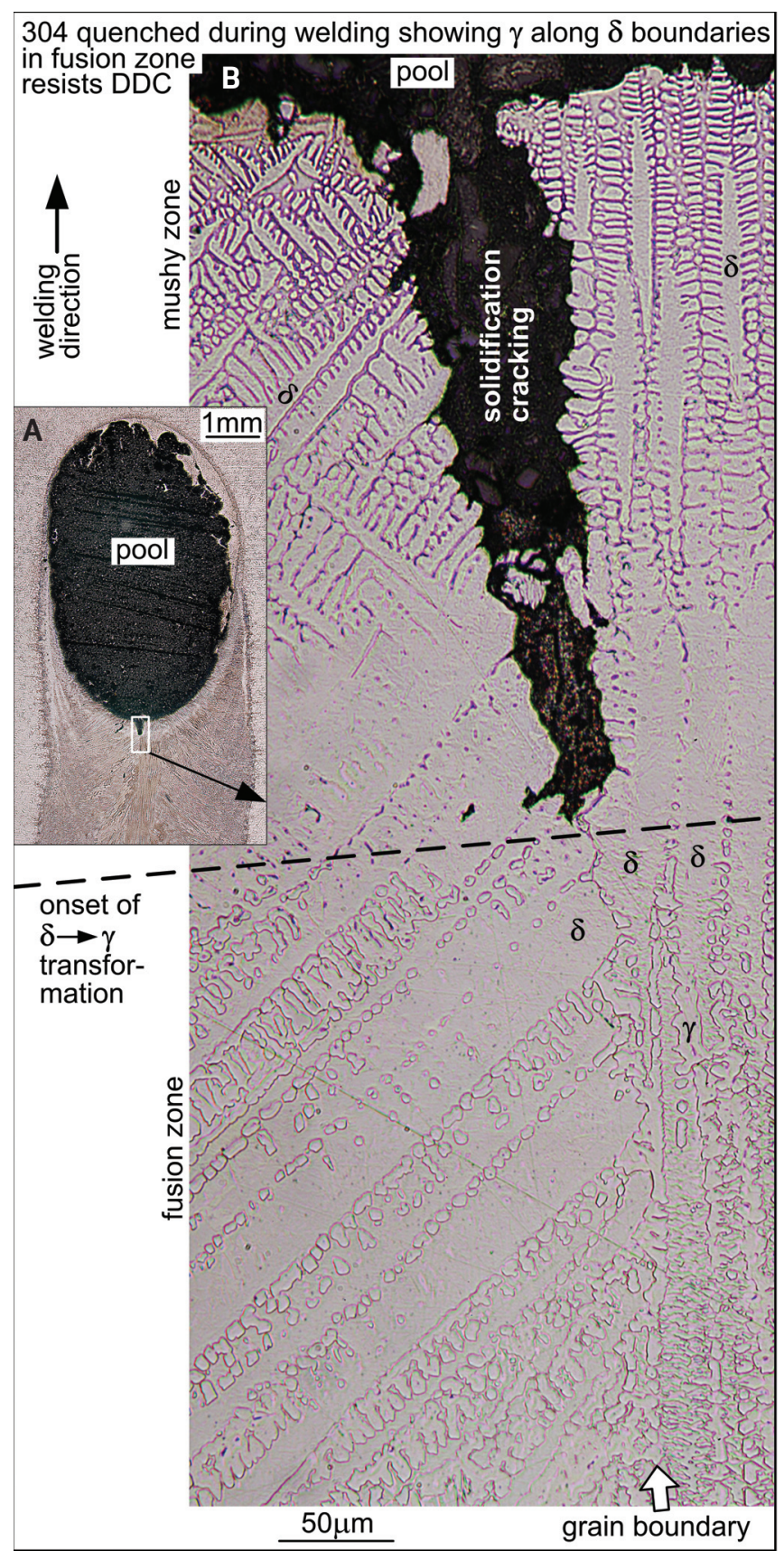

Fig. 7-304 quenched during welding: A - Macrograph; B micrograph showing solidification cracking in the mushy zone. Absence of DDC in the fusion zone suggests nearly continuous $\gamma$ along the boundaries between $\delta$ dendrites resists $D D C$.

Quenching during welding is useful for understanding the mechanism of resistance to DDC because the elevatedtemperature microstructure responsible for the resistance can be captured simultaneously when DDC is induced. The elevated-temperature microstructure of the fusion zone near the mushy zone, where DDC occurs during welding, can be related to the resistance (or susceptibility) to DDC to identify the mechanism responsible for the resistance to DDC.

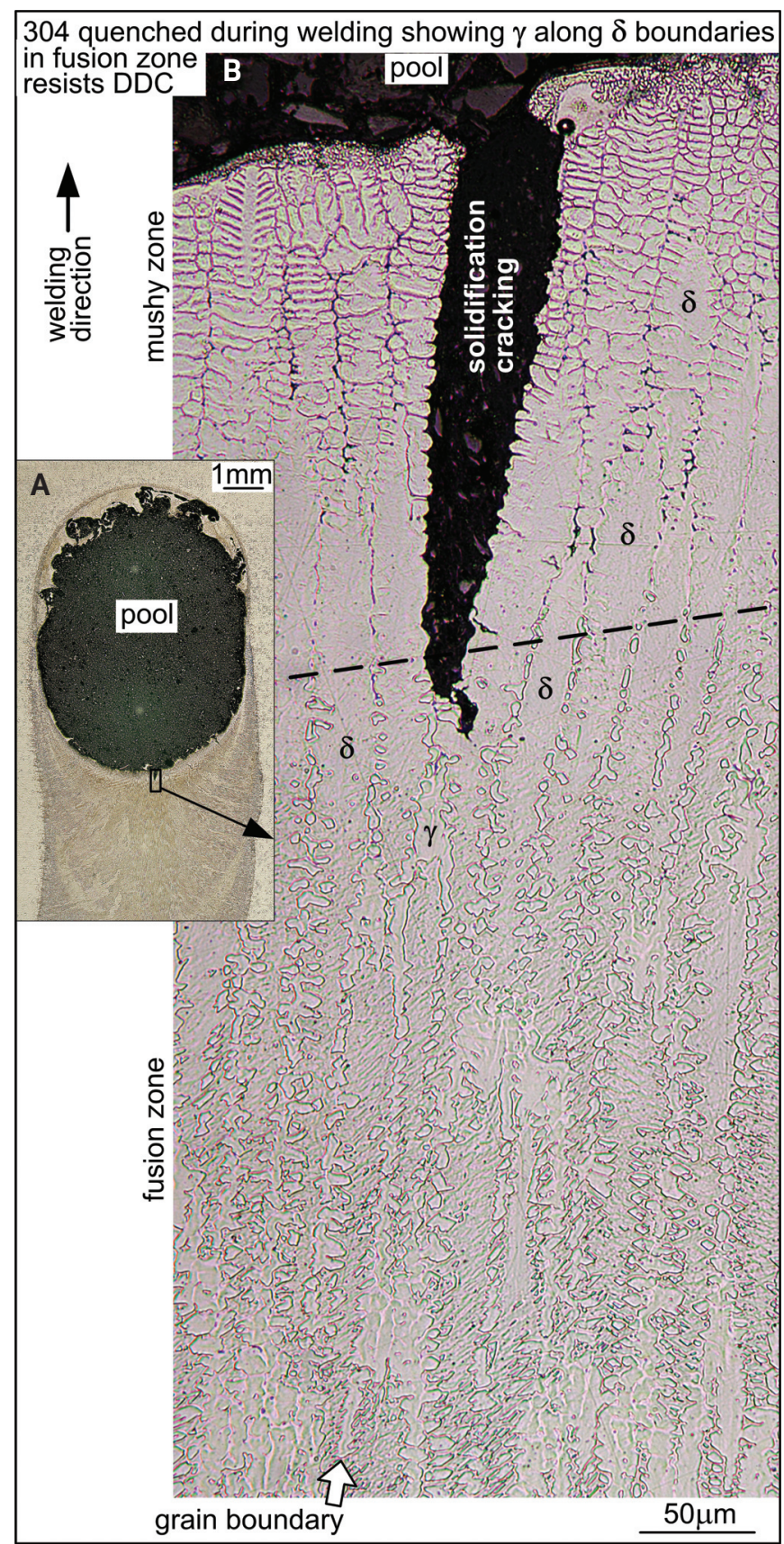

Fig. 8 - Another 304 quenched during welding: A - Macrograph; B - micrograph showing solidification cracking in the mushy zone. Again, the absence of DDC in the fusion zone suggests nearly continuous $\gamma$ along boundaries between $\delta$ dendrites resists DDC.

\section{Stainless Steel}

Figure 7 is an example of the microstructure of 304 stainless steel quenched during welding. The thick, dark broken line in Fig. 7B indicates the onset of the formation of $\gamma$ along boundaries between columnar $\delta$ dendrites. This formation is caused by the $\delta \rightarrow \gamma$ transformation when the two-phase region of $(\delta+\gamma)$ in Fig. 2A is reached soon after solidification. Ahead of the broken line is the mushy zone near the weld 
pool. Solidification cracking occurs in the mushy zone along the boundary between a columnar dendritic grain on the right and another on the left. This GB continues beyond the broken line into the fusion zone as indicated by the thick white arrowhead at the bottom of Fig. 7B. No cracking, however, is visible along the GB in the fusion zone behind the broken line. This suggests the nearly continuous $\gamma$ along the GB resists DDC.

A similar example of the microstructure of 304 stainless steel quenched during welding is shown in Fig. 8. Solidification cracking occurs in the mushy zone along the GB between a columnar dendritic grain on the right and another on the left. No significant cracking, however, is visible along the GB in the fusion zone behind the broken line. This again suggests the nearly continuous $\gamma$ along the GB resists DDC.

\section{Stainless Steel}

An example of the microstructure of 316 stainless steel quenched during welding is shown in Fig. 9. Again, the thick dark broken line indicates the onset of the formation of $\gamma$ along the boundaries between columnar $\delta$ dendrites in the fusion zone. Solidification cracking is evident in the mushy zone. DDC occurs in the fusion zone but is soon arrested by the $\gamma$ that forms along boundaries between $\delta$ dendrites. Thus, as in the case of 304 shown in Figs. 7 and 8, $\gamma$ along boundaries between the columnar $\delta$ dendrites in the fusion zone resists DDC.

\section{Stainless Steel}

Figure 10 shows the microstructure of 321 stainless steel quenched during welding. This case is different from the previous cases of 304 and 316 shown in Figs. 7-9. First, $\gamma$ does not form along the boundaries of $\delta$-ferrite grains until about 900 $\mu \mathrm{m}$ behind the pool boundary (about $500 \mu \mathrm{m}$ behind the crack tip). Second, $\delta$-ferrite grains are equiaxed instead of columnar. As shown by Liu et al. (Ref. 32), equiaxed grains can nucleate at TiN particles in 321 stainless steel during welding. If the $\mathrm{Ti}$ and $\mathrm{N}$ contents are significant and if the welding conditions favor nucleation of $\delta$-ferrite grains at TiN particles, solidification as equiaxed grains can occur in 321 . Since the GBs associated with equiaxed grains are tortuous, they resist crack propagation better than the long, straight GBs associated with columnar grains. Thus, it is not surprising that DDC occurs in the fusion zone but is soon arrested by the tortuous GBs of the equiaxed grains. The bottom of the mushy zone is likely near the tip of the crack. In Fig. 10A, a lighter-etching area exists behind the weld pool and is followed by a darker-etching area (also in Fig. 6C). The darker-etching area is where $\gamma$ forms along the boundaries of $\delta$-ferrite grains, as shown by Fig. 10C. Thus, the boundary between the lighter- and darker-etching areas behind the weld pool in Fig. 10A is where $\gamma$ starts to form. Thus, DDC is resisted by tortuous GBS associated with the equiaxed-dendritic solidification mode of this weld instead of by the formation of $\gamma$ along boundaries between $\delta$ dendrites.

\section{Stainless Steel}

Figure 11 is an example of the microstructure of 310

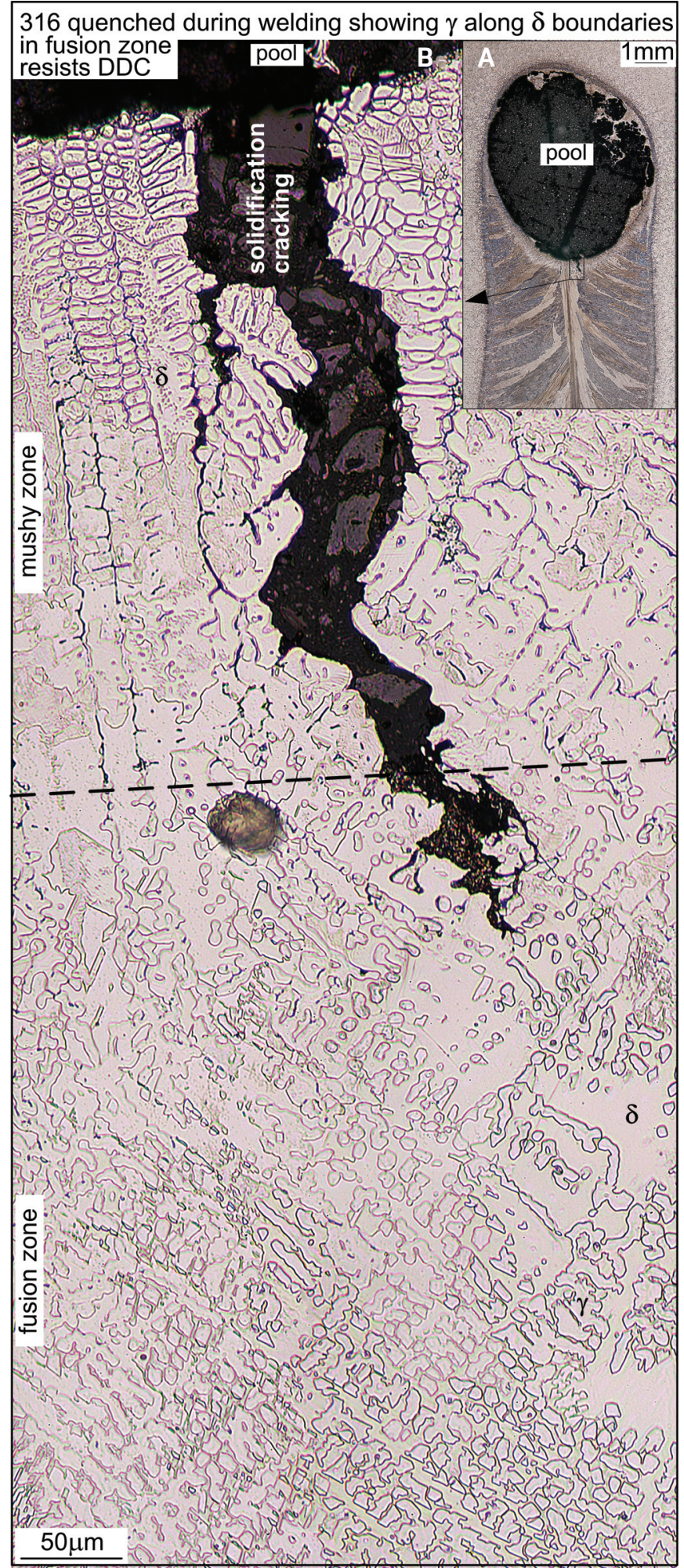

Fig. 9-316 quenched during welding: A - Macrograph; B micrograph showing solidification cracking in the mushy zone. Shallow penetration of DDC into the fusion zone suggests nearly continuous $\gamma$ along the boundaries between $\delta$ dendrites resists $D D C$. 


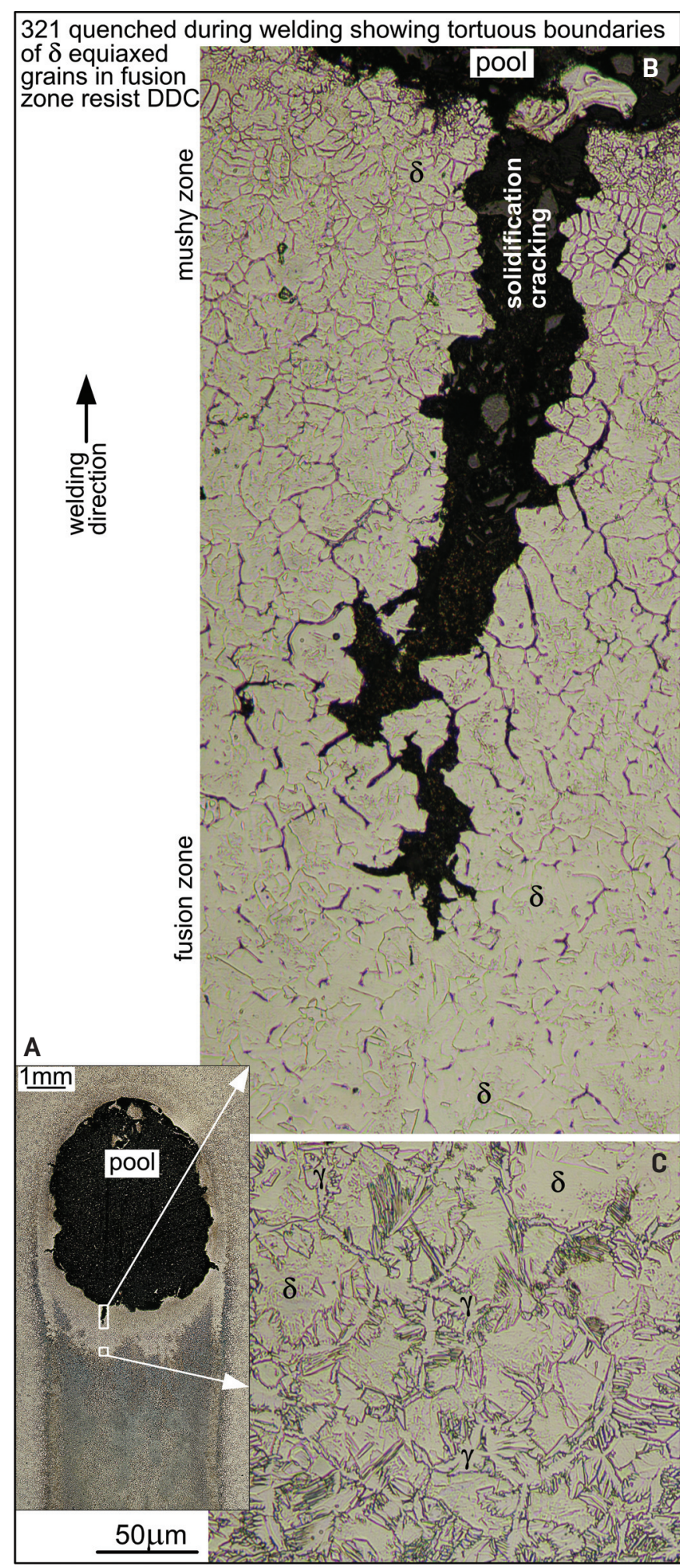

Fig. 10 - 321 quenched during welding: A - Macrograph; B micrograph showing solidification cracking in the mushy zone. Shallow penetration of DDC into the fusion zone suggests tortuous boundaries of equiaxed $\delta$-ferrite grains resist DDC. stainless steel quenched during welding. Unlike the cases of 304, 316, and 321 stainless steels, the microstructure near the pool boundary and that far behind it are similar, as shown in Fig. 11A. In other words, there is no evidence of solid-state transformation after the end of solidification. This is consistent with the vertical section of the $\mathrm{Fe}-\mathrm{Cr}-\mathrm{Ni}$ phase diagram in Fig. 2B. As indicated by the vertical dotted line, 310 (approximately Fe-25Cr-20Ni in composition) should solidify as primary austenite $\gamma$. When the threephase triangle of $(\delta+\gamma+\mathrm{L})$ is reached during solidification, some interdendritic $\delta$ should form. After solidification is over, however, the alloy does not cool down into the twophase region of $(\delta+\gamma)$. Consequently, there should be no solid-state $\gamma \rightarrow \delta$ transformation after solidification ends.

As compared to the cases of 304, 316, and 321 shown in Figs. 7-10, cracking near the pool boundary, that is, solidification cracking, is much more severe in 310. As mentioned previously, this is consistent with the experimental results of Arata et al. (Ref. 38) and Senda et al. (Ref. 39) based on the Varestraint test and Liu et al. (Ref. 32) based on the transverse-motion weldability test. Well behind the pool boundary, cracking is also evident, much more than in the cases of 304,316 , and 321. Thus, DDC is much more severe in 310 than in 304,316 , and 321. As also mentioned previously, this is consistent with the experimental results of Arata et al. (Ref. 13) based on the Varestraint test and Nissley et al. (Ref. 14) based on the strainto-fracture test.

As can be seen in Fig. 11A, 310 solidifies as coarse, straight, columnar dendrites. Similar dendrites in 310 have been identified as $\gamma$ dendrites by EBSD (Ref. 31). Liu et al. (Ref. 32) showed that, unlike the $\delta$ dendrites in 304, $\gamma$ dendrites in 310 do not start to bond to each other to resist tension and, hence, solidification cracking until very late in solidification. In other words, liquid films persist along the boundaries between dendrites to keep them from bonding to each other to resist solidification cracking. There can be two reasons for this delayed bonding. First, back diffusion, which diminishes the GB liquid, is much slower in FCC $(\gamma)$ than in BCC $(\delta)$. Dendrite arms are very clear in 310 not only near the pool boundary but even far behind it. For instance, just to the right of the label SGB in Fig. 11D, an array of clear secondary dendrite arms can be seen even though they are far behind the pool boundary. They are as clear as the secondary dendrite arms near the pool boundary shown in Fig. 11B. The very clear secondary dendrite arms far behind the pool boundary are a clear indication of slow back diffusion. Second, the amount of interdendritic $\delta$ formed in 310 is small, that is, not much liquid $\mathrm{L}$ is consumed by the ( $\delta$ $+\gamma+L)$ three-phase reaction. So, neither back diffusion nor the three-phase reaction significantly helps deplete the grain-boundary liquid in 310 .

Thus, $\delta$ dendrites in 304 can bond to each other early to resist solidification cracking, but $\gamma$ dendrites in 310 are still separated by continuous liquid films late in solidification. This explains why 310 is much more susceptible to solidification cracking than 304 . Liu et al. (Ref. 28) showed backed diffusion diminished GB liquid in $\mathrm{Al}-4 \mathrm{Mg}$ alloy and caused early bonding of dendrites to resist solidification cracking, which is much better resistance than $\mathrm{Al}-4.4 \mathrm{Cu}$.

After solidification is over, the coarse, straight, columnar grains in 310 still promote cracking, that is, DDC. As can be 




Fig. $11-310$ stainless steel quenched during welding: A - Microstructure closely behind the weld pool showing DDC deep into the fusion zone as well as SC; B - SC; C-E - DDC along the straight migrated grain boundaries (MGBS).

seen in Fig. 11C-E, there is little $\delta$ along the SGBs, and SGBs migrate to become locally straight MGBs. Thus, the long, straight, naked MGBs become ideal paths for DDC. This explains the high susceptibility of 310 to DDC.

\section{Mechanisms of Resistance of Stainless Steels to DDC}

As mentioned previously, in Ni-based alloys, precipitates that form along GBs during terminal solidification have been shown to pin GBs and resist DDC. This mechanism has been verified in Ni-based alloys (Refs. 6, 7). The fact that the fusion zones of austenitic stainless steels resisting DDC show skele- tal/lacy $\delta$ in a matrix of $\gamma$ often leads one to suggest that skeletal/lacy $\delta$ resists DDC because it pins GBs (Refs. 14, 40, 41).

Lee et al. (Ref. 40) studied hot cracking in flux cored arc welding of 304 with welding wires varying in both the $\mathrm{Cr}$ and $\mathrm{Ni}$ contents. DDC was observed in a weld containing $16.7 \mathrm{wt}-\% \mathrm{Cr}$ and $14.0 \mathrm{wt}-\% \mathrm{Ni}$. Its fusion zone showed columnar $\gamma$ dendrites, thus indicating primary- $\gamma$ solidification. The measured ferrite content was $0 \%$. DDC, however, was not found in a weld containing $18.5 \mathrm{wt}-\% \mathrm{Cr}$ and 10.9 wt-\% Ni. The fusion zone showed skeletal/lacy ferrite, and the measured ferrite content was $12.2 \%$. It was pointed out that, in the weld with $0 \%$ ferrite, MGBs and DDC were straight because no ferrite existed to pin GBs to resist DDC. 


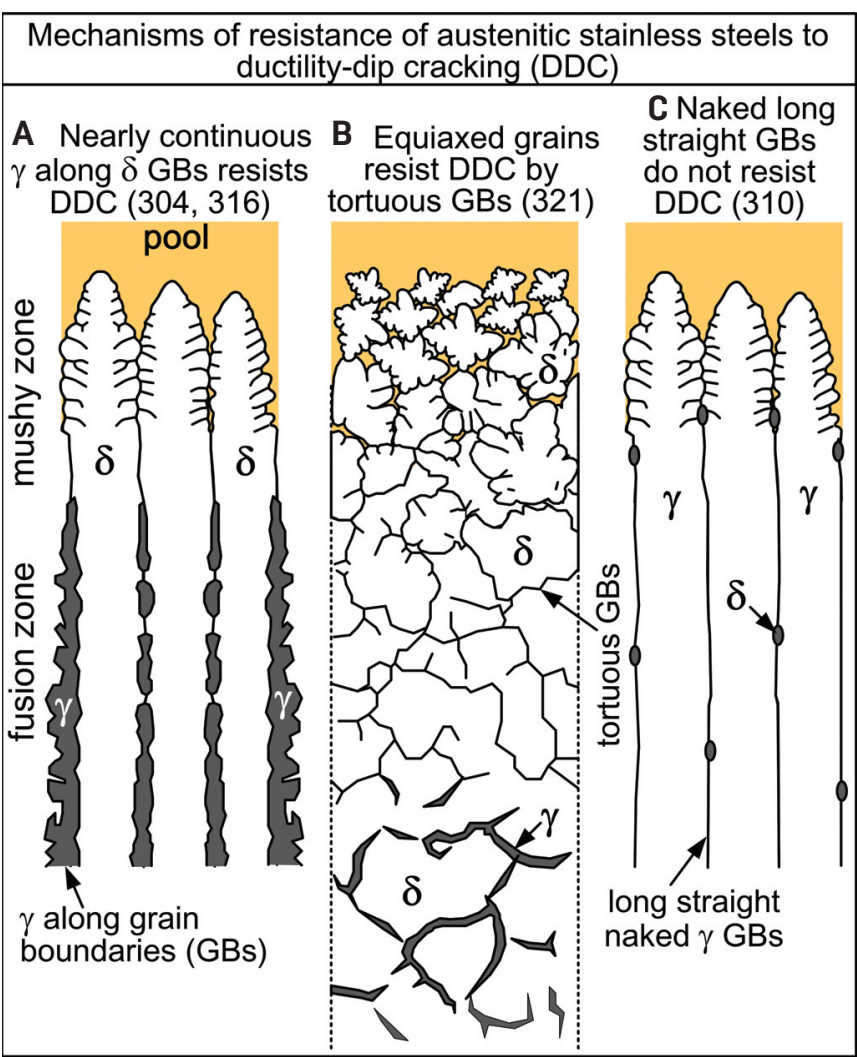

Fig. 12 - Mechanisms of resistance of austenitic stainless steels to ductility-dip cracking: A - Nearly continuous $\gamma$ along boundaries between columnar $\delta$ dendrites resists $D D C$; $B-$ tortuous boundaries between equiaxed $\delta$-ferrite grains resist DDC; $C$ - long, straight, naked boundaries between columnar $\gamma$ dendrites unable to resist DDC. Skeletal/lacy $\delta$ is not a mechanism as often suggested because it does not even exist in the fusion zone near the mushy zone, where DDC occurs.

Jang et al. (Ref. 41) studied DDC in flux cored arc welding of 316L with welding wires varying in both the $\mathrm{Cr}$ and $\mathrm{Ni}$ contents. It was reported that no DDC occurred when skeletal/lacy $\delta$ existed in the $\gamma$ matrix because the GBs were tortuous due to the pinning effect of the skeletal/lacy $\delta$.

Based on the elevated-temperature microstructure of 304, 316, and 321 shown in Figs. 7-10, two mechanisms of resistance to DDC are possible. The first mechanism, as illustrated in Fig. 12A, is the formation of nearly continuous $\gamma$ along boundaries of columnar $\delta$ grains. The second is solidification as equiaxed $\delta$ grains as illustrated in Fig. 12B. Skele$\mathrm{tal} /$ lacy $\delta$ does not exist in the fusion zone near the mushy zone, where DDC occurs during welding. Thus, skeletal/lacy $\delta$ cannot resist DDC, as has been suggested. GBs that are long, straight, and essentially naked, such as those in 310 stainless steel, have poor resistance to DDC. This is illustrated in Fig. 12C.

\section{Conclusions}

1. The mechanisms of the resistance of austenitic stainless steels to DDC were investigated by quenching 304, 310, 316 , and 321 with liquid Wood's metal during welding. Quenching captured the elevated-temperature microstruc- ture in the region of the fusion zone closely behind the mushy zone, where DDC occurs, and simultaneously induced DDC. This novel technique revealed how the microstructure resisted DDC and hence the mechanisms of the resistance to DDC.

2. The susceptibility to DDC induced by Wood's metal quenching was much more severe in 310 than in 304, 316, and 321, which is consistent with the experimental results of Arata et al. (Ref. 13) based on the Varestraint test and Nissley et al. (Ref. 14) based on the strain-to-fracture test.

3. 304 and 316 both solidified as columnar $\delta$ grains and a $\delta \rightarrow \gamma$ transformation occurred soon after solidification, resulting in the formation of a nearly continuous $\gamma$ along the boundaries between columnar $\delta$ grains. Since $\gamma$ grows deep into $\delta, \delta$ grains are bonded together firmly by $\gamma$ to better resist DDC along $\delta$ GBs.

4. 321 solidified as equiaxed $\delta$ grains (likely by heterogenous nucleation at TiN particles), and the tortuous boundaries associated with equiaxed grains resisted DDC.

5. 310 solidified as coarse, straight, columnar grains of $\gamma$ with little $\delta$ along GBs, and the GBs migrated to become locally straight. The resulting long, straight, and naked GBs became ideal paths for DDC.

6 . The present study showed two new mechanisms for the resistance of austenitic stainless steels to DDC: 1 ) formation of nearly continuous $\gamma$ along boundaries of columnar $\delta$ grains and 2 ) solidification as equiaxed $\delta$ grains. It also showed that skeletal/lacy $\delta$ cannot resist DDC as widely believed because it does not even exist in the region of the fusion zone near the mushy zone, where DDC occurs during welding.

\section{Acknowledgment}

This work was supported by the National Science Foundation under Grant No. DMR1904503.

\section{References}

1. Kou, S. 2020. Welding Metallurgy, $3^{\text {rd }}$ ed. Hoboken, N.J.: John Wiley and Sons Inc., pp. 323-377.

2. Lippold, J. C. 2015. Welding Metallurgy and Weldability. Hoboken, N.J.: John Wiley \& Sons.

3. Flemings, M. C. 1974. Solidification Processing. New York, N.Y.: McGraw-Hill, pp. 252-256 and Appendix B.

4. Nivikov, I. I. April 1962. Alloying non-ferrous alloys to reduce hot tearing. Russian Castings Production, pp. 167-172.

5. Rhines, F. N., and Wray, P. J. 1961. Investigation of the intermediate temperature ductility minimum in metals. ASM TRANS $Q$ 54(2): 117-128.

6. Ramirez, A. J., and Lippold, J. C. 2004. High temperature behavior of Ni-base weld metal: Part II - Insight into the mechanism for ductility dip cracking. Materials Science and Engineering $A$ 380(1): 245-258. DOI: 10.1016/j.msea.2004.03.075

7. Ramirez, A. J., and Lippold, J. C. 2005. New insight into the mechanism of ductility-dip cracking in Ni-base weld metals. Hot Cracking Phenomena in Welds. Springer Berlin Heidelberg, pp. 19-41.

8. Noecker II, F. F., and DuPont, J. N. 2009. Metallurgical investigation into ductility dip cracking in Ni-based alloys: Part I. Welding Journal 88(1): 7-s to 20-s.

9. Noecker II, F. F., and DuPont, J. N. 2009. Metallurgical investigation into ductility dip cracking in Ni-based alloys: Part II. Weld- 
ing Journal 88(3): 62-s to 77-s.

10. Nishimoto, K., Saida, K., and Okauchi, H. 2006. Microcracking in multipass weld metal of alloy 690 Part 1 - Microcracking susceptibility in reheated weld metal. Science and Technology of Welding and Joining 11(4): 455-461. DOI: 10.1179/174329306X 94291

11. Nishimoto, K., Saida, K., Okauchi, H., and Ohta, K. 2006. Microcracking in multipass weld metal of alloy 690 Part $2-$ Microcracking mechanism in reheated weld metal. Science and Technology of Welding and Joining 11(4): 462-470. DOI: 10.1179/ 174329306X94309

12. Nishimoto, K., Saida, K., Okauchi, H., and Ohta, K. 2006. Microcracking in multipass weld metal of alloy 690 Part 3 - Prevention of microcracking in reheated weld metal by addition of $\mathrm{La}$ to filler metal. Science and Technology of Welding and Joining 11(4): 471-479. DOI: 10.1179/174329306X94318

13. Arata, Y., Matsuda, F., and Katayama, S. 1977. Solidification crack susceptibility in weld metals of fully austenitic stainless steels. Report II. Trans. JWRI: 105-116.

14. Nissley, N. E., Collins, M. G., Guaytima, G., and Lippold, J. C. 2002. Development of the strain-to-fracture test for evaluating ductility-dip cracking in austenitic stainless steels and Ni-base alloys. Welding in the World 46(7-8): 32-40.

15. Nishimoto, K., Saida, K., Kiuchi, K., and Nakayama, J. 2011. Influence of minor and impurity elements on hot cracking susceptibility of extra high-purity type 310 stainless steels. Hot Cracking Phenomena in Welds III. Eds. Lippold, J., Bollinghaus, T., and Cross, C. E. Springer-Verlag, Berlin, pp. 183-208.

16. Shibata, S., and Watanabe, T. 1999. Direction of grainboundary migration in the weld metal of an austenitic stainless steel. Metallurgical and Materials Transactions A 30: 612-626.

17. Kou, S., and Le, Y. 1982. The effect of quenching on the solidification structure and transformation behavior of stainless steel welds. Metallurgical and Materials Transactions A 13(7): 1141-1152.

18. Brooks, J. A., and Garrison Jr., W. M. 1999. Weld microstructure development and properties of precipitation-strengthened martensitic stainless steels. Welding Journal 78(8): 280-s to 291-s.

19. Inoue, H., Koseki, T., Ohkita, S., and Fuji, M. 2000. Formation mechanism of vermicular and lacy ferrite in austenitic stainless steel weld metals. Science and Technology of Welding and Joining 5(6): 385-396. DOI: 10.1179/136217100101538452

20. Koseki, T., Matsumiya, T., Yamada, W., and Ogawa, T. 1994. Numerical modeling of solidification and subsequent transformation of Fe-Cr-Ni alloys. Metallurgical and Materials Transactions A 25(6): 1309-1321.

21. Inoue, H., Koseki, T., Okita, S., and Fuji, M. 1997. Solidification and transformation behaviour of austenitic stainless steel weld metals solidified as primary austenite: Study of solidification and subsequent transformation of $\mathrm{Cr}$-Ni stainless steel weld metals ( $2^{\text {nd }}$ Report). Welding International 11(12): 937-949.

22. Komizo, Y. I., Terasaki, H., Yonemura, M., and Osuki, T. 2005. In-situ observation of steel weld solidification and phase evolution using synchrotron radiation. Transactions of JWRI 34(2): 51-55.

23. Yonemura, M., Osuki, T., Terasaki, H., Komizo, Y., Sato, M., and Kitano, A. 2006. In-situ observation for weld solidification in stainless steels using time-resolved x-ray diffraction. Materials Transactions 47(2): 310-316.

24. Inoue, H., Koseki, T., Ohkita, S., and Tanaka, T. 1995. Effect of solidification on subsequent ferrite-to-austenite massive transformation in an austenitic stainless steel weld metal. ISIJ International 35(10): 1248-1257.

25. Villafuerte, J. C., Kerr, H. W., and David, S. A. 1995. Mechanisms of equiaxed grain formation in ferritic stainless steel gas tungsten arc welds. Materials Science and Engineering A 194(2): 187-191.

26. Koseki, T., Inoue, H., Fukuda, Y., and Nogami, A. 2003. Nu- merical simulation of equiaxed grain formation in weld solidification. Science and Technology of Advanced Materials 4(2): 183-195. DOI: 10.1016/S1468-6996(03)00026-3

27. Matsuda, F., Nakagawa, H., and Lee, J.-B. 1987. Weld cracking in duplex stainless steel (Report I). Transactions of JWRI 16(2): 343-349.

28. Liu, J., Duarte, H. P., and Kou, S. 2017. Evidence of back diffusion reducing cracking during solidification. Acta Materialia 122: 47-59. DOI: 10.1016/j.actamat.2016.09.037

29. Milne, G. W. A. Gardner's Chemical Synonyms and Trade Names. New York, N.Y.: John Wiley \& Sons.

30. amazon.com/Melting-Point-Alloy-Fields-Metal/dp/ B001QUXA8M

31. Yu, P., Thompson, K. J., McCarthy, J., and Kou, S. 2018. Microstructure evolution and solidification cracking in austenitic stainless steel welds. Welding Journal 97(11): 301-s to 314-s. DOI: 10.29391/2018.97.026

32. Liu, K., Yu, P., and Kou, S. 2020. Solidification cracking susceptibility of stainless steels: New test and explanation. Welding Journal 99(10): 255-s to 270-s. DOI: 10.29391/2020.99.024

33. Elmer, J. W., Wong, J., and Ressler, T. 1998. Spatially resolved X-ray diffraction phase mapping and $\alpha \rightarrow \beta \rightarrow \alpha$ transformation kinetics in the heat-affected zone of commercially pure titanium arc welds. Metallurgical and Materials Transactions A 29 2761-2773.

34. Elmer, J. W., Wong, J., and Ressler, T. 2000. In-situ observations of phase transformations during solidification and cooling of austenitic stainless steel welds using time-resolved x-ray diffraction. Scripta Materialia 43(8): 751-757. DOI: 10.1016/S13596462(00)00481-4

35. Babu, S. S., Elmer, J. W., Vitek, J. M., and David, S. A. 2002. Time-resolved x-ray diffraction investigation of primary weld solidification in Fe-C-Al-Mn steel welds. Acta Materialia 50(19): 4763-4781. DOI: 10.1016/S1359-6454(02)00317-8

36. Hillert, M., and Qiu, C. 1990. A reassessment of the Cr-FeNi system. Metallurgical Transactions A 21(6): 1673-1680.

37. Lippold, J. C., and Savage, W. F. 1979. Solidification of austenitic stainless steel weldments: Part 1 - A proposed mechanism. Welding Journal 58(12): 362-s to 374-s.

38. Arata, Y., Matsuda, F., and Saruwatari, S. 1974. Varestraint test for solidification crack susceptibility in weld metal of austenitic stainless steels. Transactions of JWRI 3(1): 79-88.

39. Senda, T., Matsuda, F., Takano, G., Watanabe, K., Kobayashi, T., and Matsuzaka, T. 1971. Fundamental investigations on solidification crack susceptibility for weld metals with trans-varestraint test. Transactions of the Japan Welding Society 2(2): 141-162.

40. Lee, D. J., Byun, J. C., Sung, J. H., and Lee, H. W. 2009. The dependence of crack properties on the $\mathrm{Cr} / \mathrm{Ni}$ equivalent ratio in AISI 304L austenitic stainless steel weld metals. Materials Science and Engineering A 513-514: 154-159. DOI: 10.1016/j.msea. 2009.01.049

41. Jang, A. Y., Lee, D. J., Lee, S. H., Shim, J. H., Kang, S. W., and Lee, H. W. 2011. Effect of $\mathrm{Cr} / \mathrm{Ni}$ ratio on ductility-dip cracking in AISI 316L weld metals. Materials and Design 32(1): 371-376. DOI: 10.1016/j.matdes.2010.06.016

PING YU, formerly an assistant scientist, and SINDO KOU (kou@engr.wisc.edu), a professor, are with the Department of Materials Science and Engineering, University of Wisconsin, Madison, Wis. JUSTIN MORROW, a scientist, is with Thermo Fisher Scientific, Madison, Wis. 